\title{
Matéria
}

ISSN 1517-7076

Revista Matéria, v. 16, n. 4, pp. 867 - 876, 2011

http://www.materia.coppe.ufrj.br/sarra/artigos/artigo11463

\section{Innovation in X-Ray technology}

SCHULZ, J. W.

Business Unit X-Ray, Dipl-Ing Electrical Engineering-COMET AG, Switzerland

e-mail: johann.schulz@comet.ch

\section{ABSTRACT}

In the Non-Destructive Testing (NDT) industry, the mayor trends are from film and stand alone applications to digital and inline inspection. Furthermore the quality requirements are growing driven by pushing design and material limits. Especially for field applications based on security reasons as well as image quality, replacement of isotopes can be monitored.

With the move to digital the need for small focal spots at increased power requirements brought new challenges to the $\mathrm{x}$-ray supplier. With the move to inline inspection systems, requirements for high uptime, fast throughput at the best possible resolution became the key challenges for the x-ray industry.

The target to replace isotopes brings high challenges for weight size and energy.

The innovation program of COMET delivers solutions for those challenges.

Comparison between 600 Kilovolts $(\mathrm{kV})$ and conventional $450 \mathrm{kV}$ x-ray sources will show the advantages in penetration and resolution and with this in defect recognition.

The resolution gain with adaptive focal spots compared to standard focal spots will be presented and the advantages of maintenance reduced high voltage cables will be shown.

Keywords: Non destructive testing, X-rays, digital inspection.

\section{INTRODUCTION}

As in all industries also in NDT the major trends are the business drivers. The biggest challenges for companies are to find them, adapt them to their target markets and set the right targets for their R\&D departments [1] .

In 2002 COMET made a market analysis [2] in order to find the major trends for the industrial XRay market. The market analysis was based on the PEST principle (Figure1).

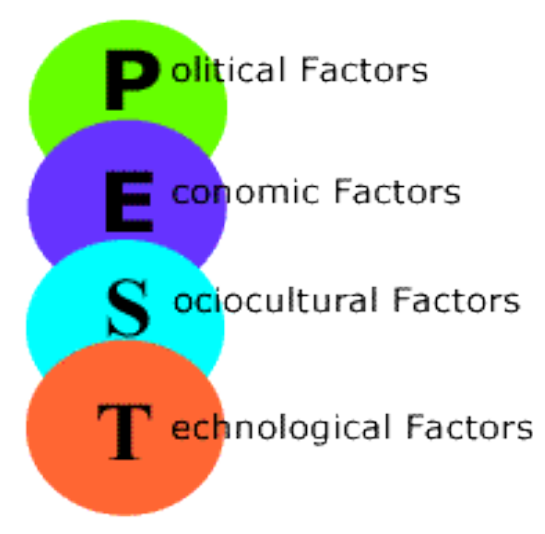

wnw.marketingteacher.com

Figure 1: PEST illustration. 
The idea was to look at your market from the different point of views mentioned above and try to look for developments, trends and hints to find mega trends which then can be applied on the different NDT markets.

We found three mega trends

$$
\begin{array}{ll}
\checkmark & \text { security } \\
\checkmark & \text { communication } \\
\checkmark & \text { miniaturization }
\end{array}
$$

They do not really look astonishing; most people will say they are obvious however the big question is how can we adopt these megatrends to the industrial x-ray markets? What do they mean for the NDT market?

Let's have a look at the different trends and try to describe each trend from a NDT standpoint:

Table 1: NDT standpoints.

\begin{tabular}{c|l}
\hline \multicolumn{1}{c|}{ SECURITY: } & $\begin{array}{l}\text { Reduce the risk of radiation accidents, make transportation and handling safer. } \\
\text { Challenge for x-ray manufacturer: replace isotopes. }\end{array}$ \\
\hline COMMUNICATION: & $\begin{array}{l}\text { More and more applications are moving from a stand alone testing (after } \\
\text { production is finished) to a process integrated or process inline testing. With this } \\
\text { the requirement for reliability, availability and performance in respect of } \\
\text { throughput is increasing. Uptime combined with high through put will be the key } \\
\text { factors for system performance. } \\
\text { Challenge for x-ray manufacturer: provide maintenance free solutions, increase }\end{array}$ \\
\hline M-ray power, easy to handle, easy to install, plug and play solutions
\end{tabular}

\section{MATERIALS AND METHODOS}

\subsection{Product Developments}

Based on those findings COMET started to define a development strategy [2]]. The goal was to find solutions for the different requirements we were looking for the best customer benefits. Please see Table 2 .

Table 2: Features and Benefits.

\begin{tabular}{c|rl}
\multicolumn{1}{c|}{ Feature } & \multicolumn{1}{c}{ Customer Benefits } \\
\hline$\bullet$ Increased power & $\bullet \begin{array}{l}\text { Higher through put, better contrast } \\
\text { resolution }\end{array}$ \\
\hline$\bullet$ Smaller focal spot $[\underline{3}, \underline{4}]$ & $\bullet \begin{array}{l}\text { Higher special resolution, higher } \\
\text { detectability }\end{array}$ \\
\hline$\bullet$ Smaller size, lower weight & $\bullet \quad$ Less space occupation, easy to handle \\
\hline$\bullet$ High Energy & $\bullet \quad$ Higher penetration, one system fits all \\
\hline
\end{tabular}

\subsection{High Power}

With the development of the High Power Technology it was possible to increase the power density of target material. The following imaging demonstrates focal spots of same sizes and power. Figure 1 
represents the conventional cooling; Figure 2 shows High Power (HP) cooling. The brightness of the image represents the temperature or in other words the brighter the image the higher the temperature.

With this technology it was now possible to either double the power of a given focal spot size or to reduce the focal spot size at a given power.

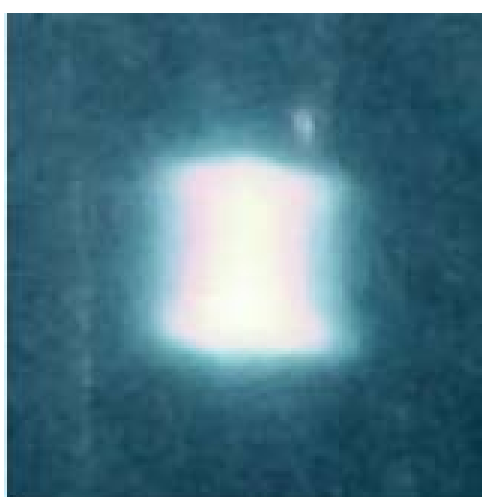

Figure 2: Conventional cooling.

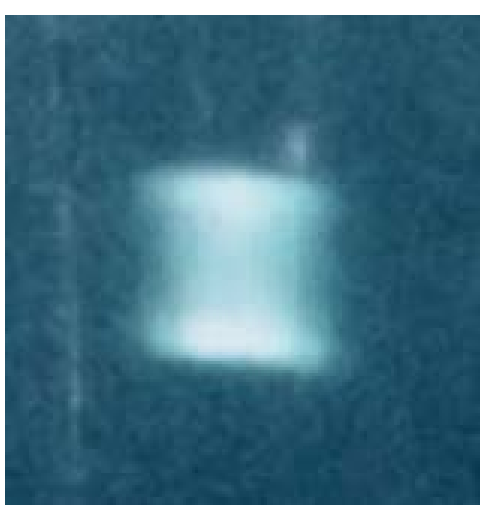

Figure 3: HP-Cooling.

\subsection{Less size - Less weight}

With the development of the MXC (Metal-ceramic X-ray tube Compact) series COMET developed a new line of bipolar tubes with much less weight and size. The concept is based on a cooling technology of the receptacles; with this it was possible to skip the additional connectors and with this the tubes are getting smaller in size and with this in weight. Figure 4 and 5 shows the difference between the new MXC-451HP11 and the regular MXR-451HP11. Both tubes provide the same x-ray power and resolution, however the weight is reduced from 95 kilograms $(\mathrm{kg})$ to $45 \mathrm{~kg}$.
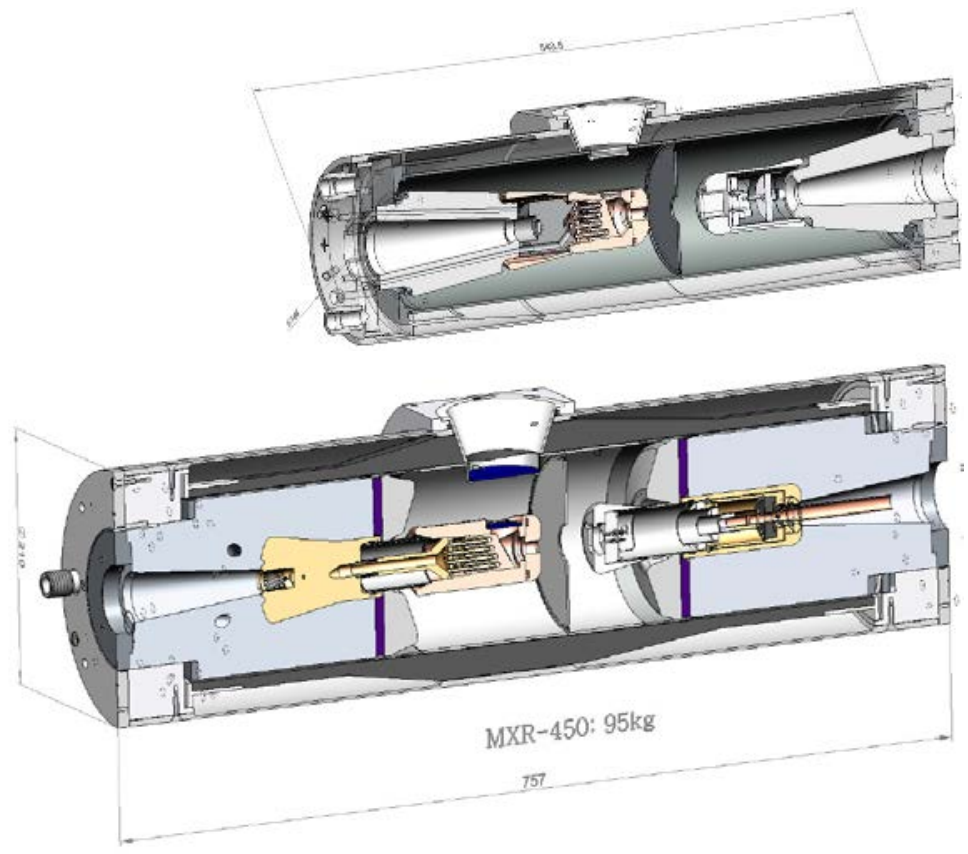

Figure 4: MXC (top) and regular MXR type. 


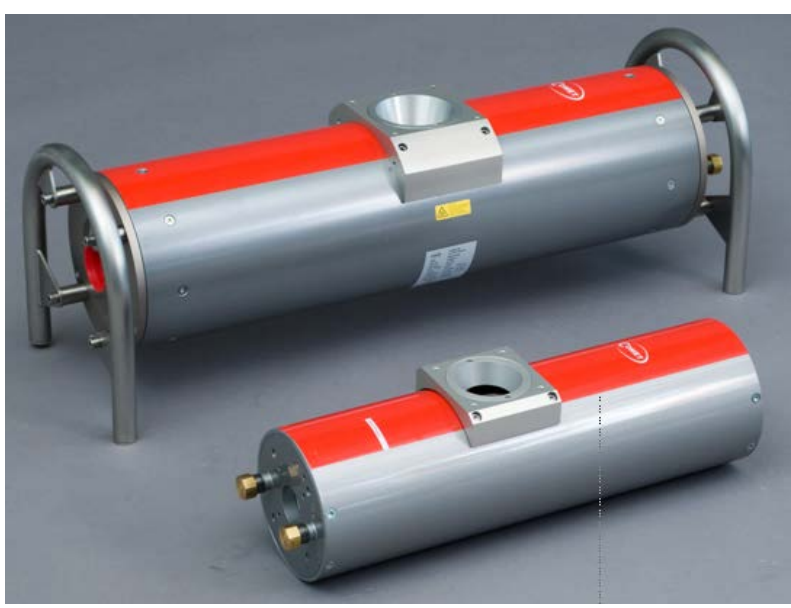

Figure 5: MXC and MXR-type.

This technology can be applied to all bipolar tubes. Figure 6 shows the X-Ray source with the new MXC-451HP11. This tube combines the HP Technology with compactness.

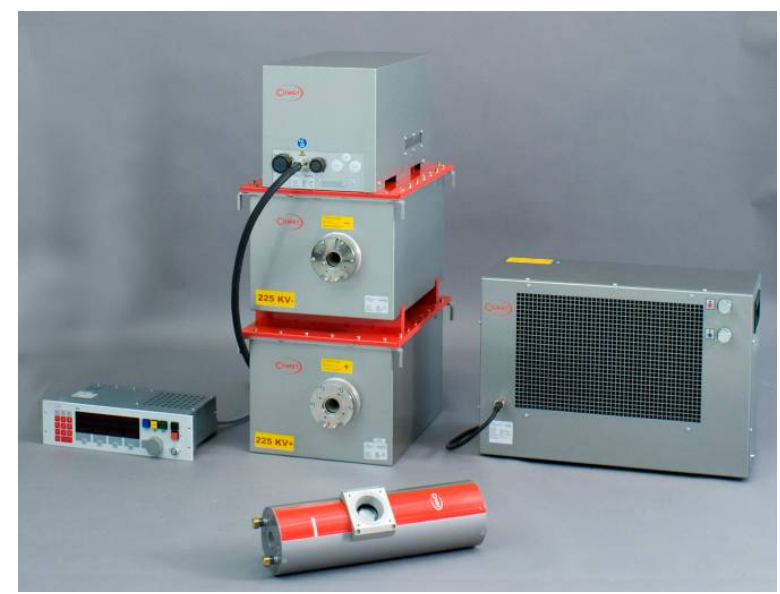

Figure 6: XRS-450 with MXC-451HP11.

\subsection{Closing the Gap: High Energy 600kV and 800kV}

With the development of the $600 \mathrm{kV}$ and $800 \mathrm{kV}$ sources (Figures 7 and 8 respectively) the gap between standard $\mathrm{x}$-ray sources and linear accelerators has been closed.

In the past if the penetration capability of standard x-ray sources (available up to $450 \mathrm{kV}$ ) was not good enough the customer had do go for linear accelerators starting from 2 Mega electron volts (MeV) or powerful isotopes. In both cases handling, safety regulations, certification and approval could be a big hurdle. Not to speak about expensive shielding!

The new high energy x-ray sources now can be adjusted to the penetration requirement. Furthermore, their handlings are well known because they behave and are operated as regular x-ray sources. A controller provides easy operation, simply choose the required kilovolt $(\mathrm{kV})$, milliamperes $(\mathrm{mA})$, exposure time and press $\mathrm{x}$-ray $\mathrm{ON}$.

The main differences in respect of handling to LINAC's are

- $\quad$ constant potential, no pulse

- $\quad$ step less control of $\mathrm{kV}$ and $\mathrm{mA}$, no fixed potential respectively power

- $\quad$ stable operation without expensive additional air condition

- $\quad$ no regular tuning necessary 


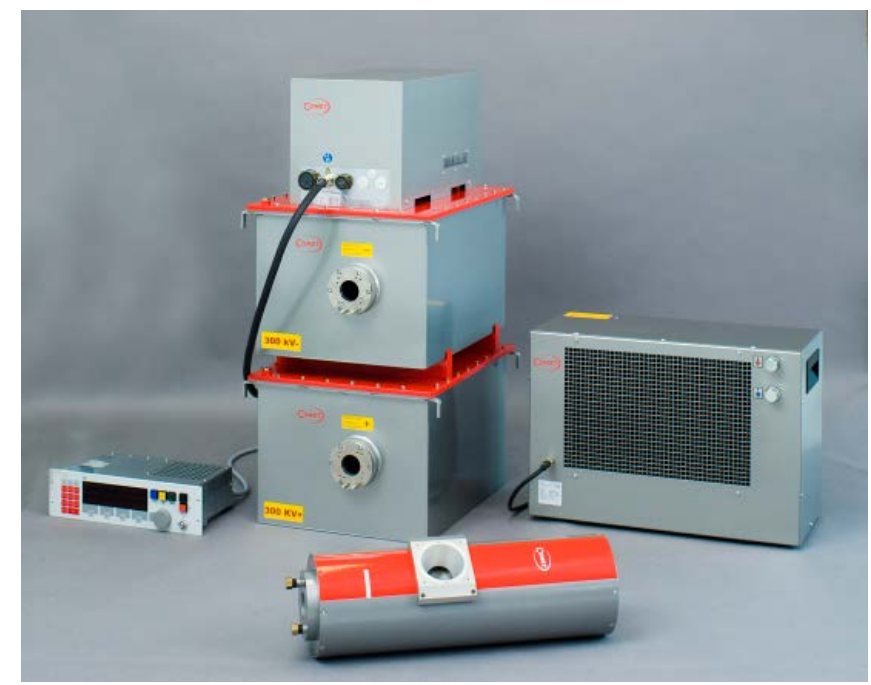

Figure 7: 600kV X-ray source.

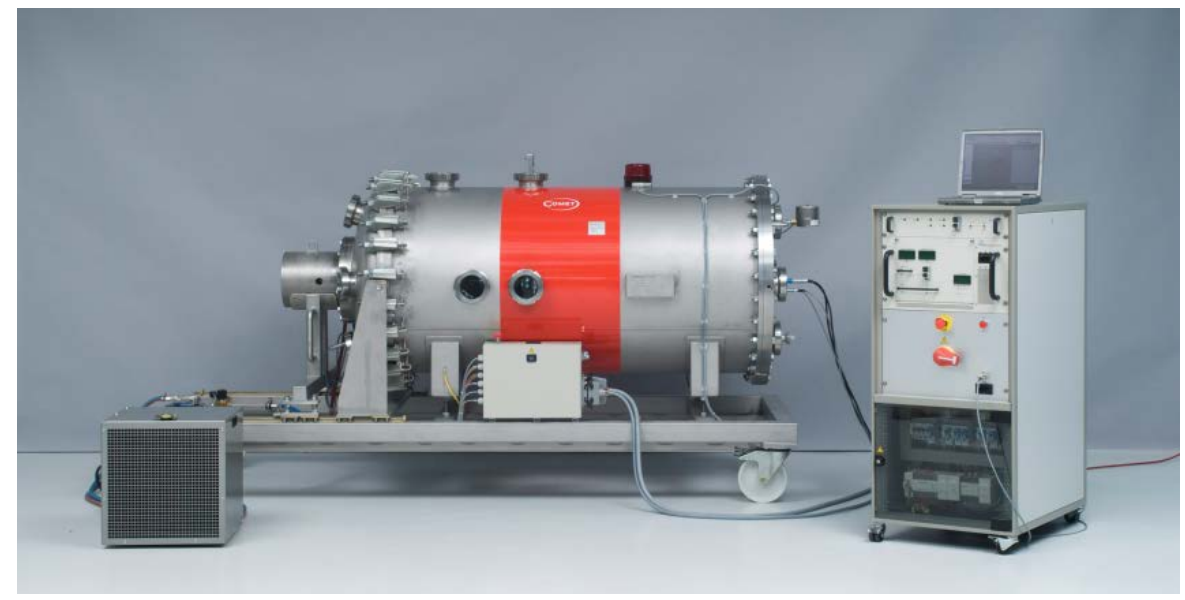

Figure 8: 800kV X-Ray Source.

\subsection{Variable Focal Spot}

The new XRS-225VF is a milestone in X-Ray development. It combines the HP-Technology with the possibility to adjust the focal spot during operation. With this the customer has always the optimum of resolution and throughput. For smaller parts he will use the smallest focal spot because here resolution is key, for bigger parts he will go for more power and less resolution. But even for bigger parts with high resolution requirements this $\mathrm{x}$-ray source is the best available solution on the market. With a effective focal spot size of about $100 \mu \mathrm{m}$ at a power of $290 \mathrm{~W}$ with a penetration capability of $225 \mathrm{kV}$ this tube can be used for a wide area of application. Especially combined with digital panels this x-ray source can be used for film replacement as well as for high resolution computed tomography (CT). In the near future this tube will be used for in-line CT.

Existing tubes for industrial applications come with fixed focal spots. Figure 9 shows the adjustable area of the focal spots. Figure 10 shows the nearly circular focal spot with a homogenous dose distribution. Because of its shape and homogenous allocation, this focal spot provides the same resolution in all directions which is key for 2D imaging or 3D CT. 


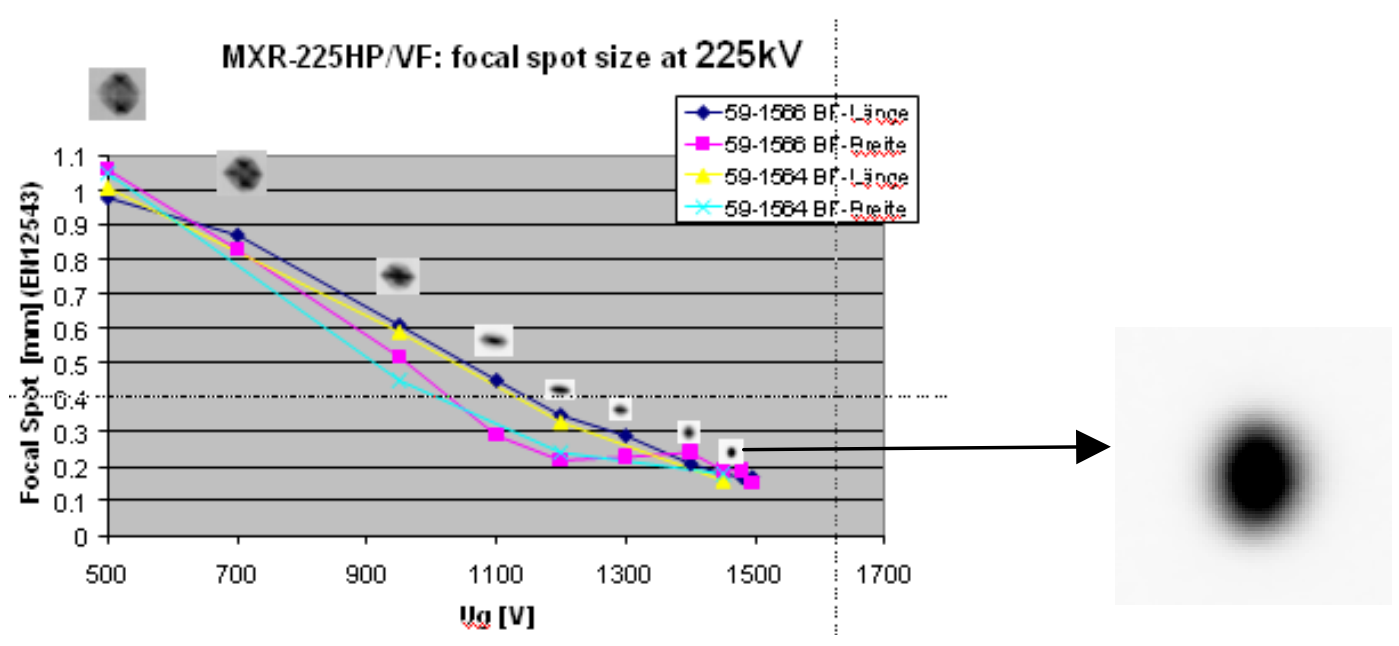

Figure 9: Adjustable focal spot sizes.

Figure 10: “Circular "focal spot.

\subsection{Spring Loaded Cable}

The high voltage connection between generator and x-ray tube is made by a high voltage cable. The interface between x-ray tube respectively generator and high voltage cable is one of the most critical and maintenance intensive parts of an x-ray source. The installation and maintenance requires a lot of experience as well as careful and proper execution. Because of this you can easily imagine that most of the failures within an x-ray source are caused by this interface.

Especially when exposed to high temperature cycles, maintenance and proper warm up becomes key for reliable and error free operation.

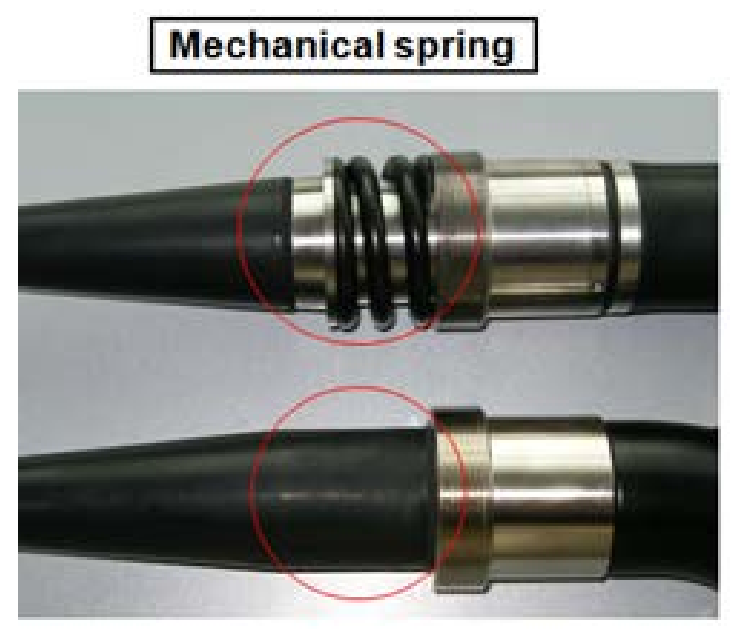

\section{Elastomeric spring}

Figure 11: New and old terminal design.

One of the weak points in the old cable design is the elastomeric spring (see Figure 11). Especially with high temperature cycles, it fatigues and with this it can not provide enough pressure to the interface. With reduced pressure the risk of flash over inside the tube receptacle increases. Furthermore with time this rubber part starts to bulge and with this the cable can not be used any more. With the new design the elastomeric spring is replaced by a mechanical spring. The big advantages here are no wear out and no bulging which means longer lifetime of the cable and constant pressure in the interface. As add on, this cable provides a "pressure" indicator with which the current interface situation can easily be checked. 


\subsection{Portable X-Ray sources}

Portable x-ray sources (Figure 12) are designed for field application. The low weight and compact size make them an ideal solution for in-field X-ray inspection. Due to high frequency switching technology, portable X-ray systems produce an extremely stable X-ray output, which leads to very short exposure times and very high image quality. Especially combined with digital detectors e.g. computed radiography (CR), digital radiography (DR), high frequency portable sources are the ideal solution for the future. The control unit (Figure 13) is microprocessor controlled and housed in a rugged, splash proof casing to fulfill the demands of rough in-field $\mathrm{X}$-ray inspection.

Kilovolts $(\mathrm{kV})$, milliamperes $(\mathrm{mA})$ and exposure time of the portable X-ray systems can be adjusted by direct keyboard entry or by selecting one of the 100 exposure programs. All operational information is available on a 2-line alphanumeric backlit display. The tube head warning lamp, pressure and temperature of the portable X-ray systems are all monitored to prevent operation in unsafe conditions. For operation supervision, data for the latest 100 exposures are recorded and can be recalled on the display or downloaded to a printer.

The portable X-ray line PXS is insensitive to power supply irregularities and has a low level of power consumption. The thin, light interconnection and power supply cables are equipped with shock resistant plugs. Along with the robust metal-ceramic X-ray tube, this leads to a very reliable, easy-to-handle portable X-ray system for industrial in-field use.

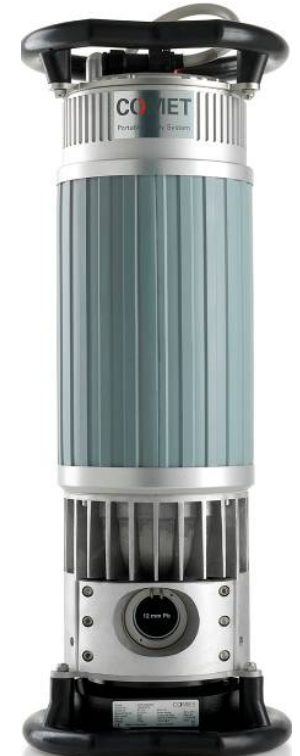

Figure 12: PXS-300.

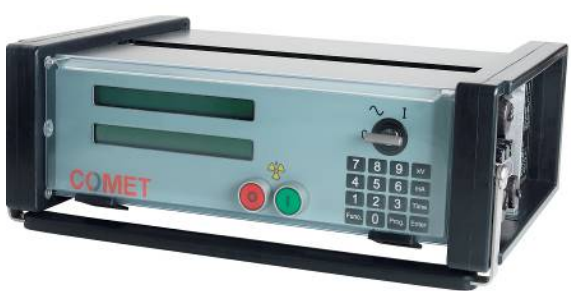

Figure 13: Control Panel.

\section{RESULTS}

\subsection{Resolution gain with HP11}

Here is demonstrated the resolution gain from a standard $450 \mathrm{kV}$ tube to a $450 \mathrm{HP}$ tube. Before the development of HP Technology the focal spots were too big for reasonable resolution of smaller parts. In those applications were resolution at medium magnification was necessary one had to use a micro focus system. With this the resolution was of course even better, however not always necessary. In most cases the failure recognizability is key, not the reachable special resolution. Not to speak about the exposure time. In this case the exposure time was cut compared to micro focus by a factor of 6. In the zoom-in part (Figures 14a and 14b) we can observe how good the special resolution really is. 


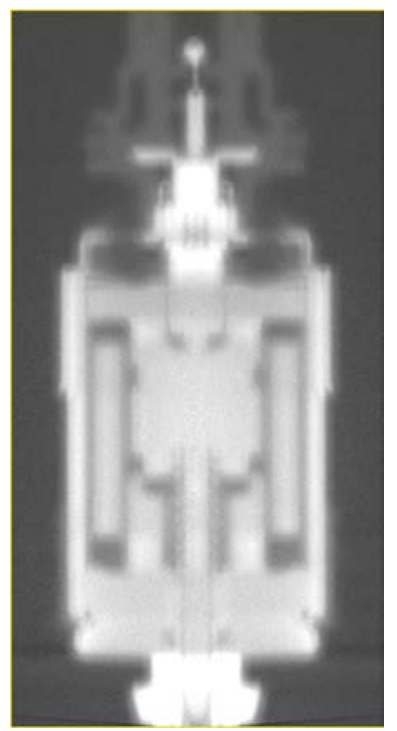

(a)

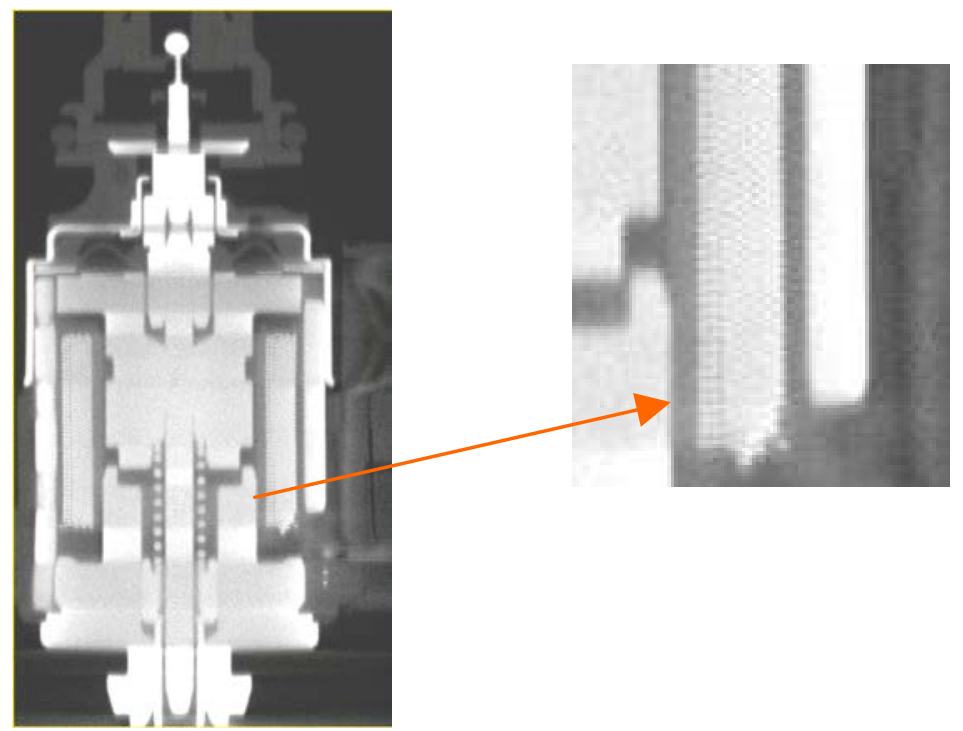

(b)

Figure 14: a) Radioscopy obtained with same $\mathrm{kV}, \mathrm{mA}$ and detector, showing the difference between standard and HP11 tubes. b) Zoom detail.

\subsection{Penetration gain with $600 \mathrm{kV}$}

The Picture 15 shows a comparison of $450 \mathrm{kV}$ with $600 \mathrm{kV}$. Both pictures were taken with HP type tubes, adopting as standard reference ASTM E1025 (2).

Test set up:

$\checkmark$ 1500Watts (W)/ 1 millimeter (mm) focal spot size;

$\checkmark$ Focus Detector Distance (FDD) $=1$ meter (m), Magnification (M)=2;

$\checkmark 32$ seconds (s) integration time;

$\checkmark$ Digital panel.
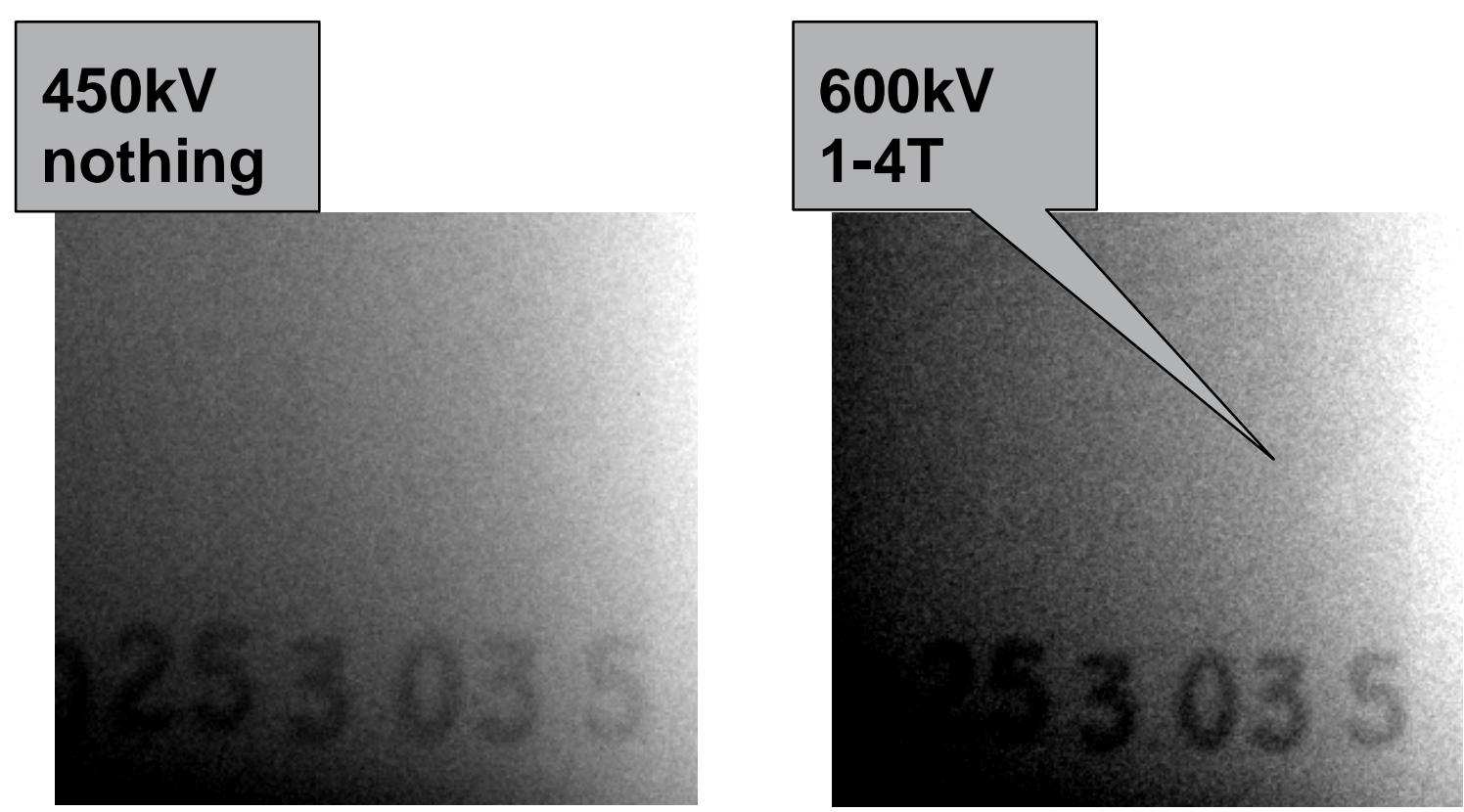

Figure 15: 81mm Inconel with ASTM* E1025 penetrameter.

Results:

For $81 \mathrm{~mm}$ Inconel a $1-4 \mathrm{~T}$ sensitivity can be achieved at $600 \mathrm{kV}$, which is not possible at $450 \mathrm{kV}$

* stands for American Society for Testing and Materials (ASTM) 
With the new x-ray source XRS-225VF horizontal and vertical the same resolution can be reached, as demonstrated by line profile histogram (Figure 16). This is unique and achieved by the nearly circular focal spot. Further more because of the homogenous and GAUSS-shaped allocation a much better resolution and brilliance can be reached.

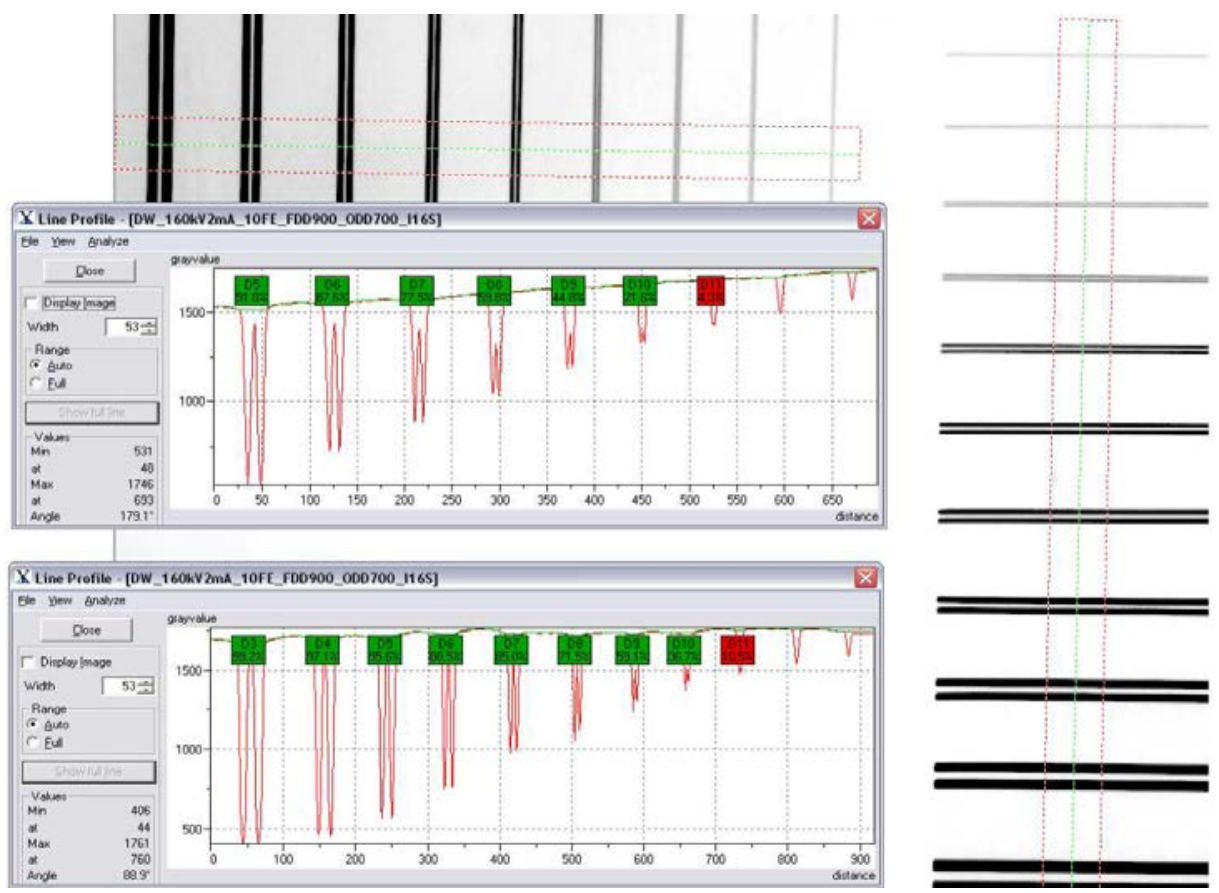

Figure 16: vertical and horizontal resolution of 225VF.

In Figure 17 a comparison of standard HP11 and VarioFocus (VF) is shown, both images were taken within the same parameters, using a pair lines standard in compliance with EN12543 ${ }^{(1)}$.The images with the VF tube demonstrate to be clearer than with HP11.
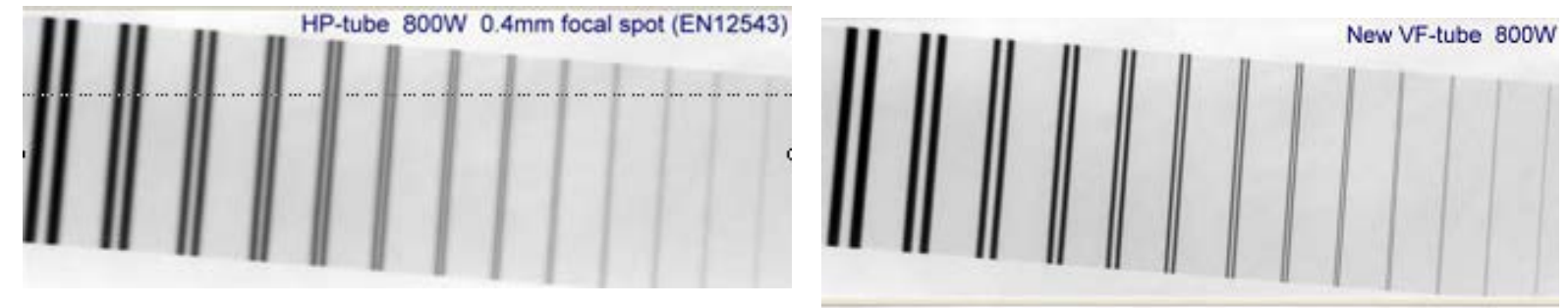

Figure 17: Images obtained with HP11 compared to VarioFocus (VF).

\section{CONCLUSION}

The requirements for x-ray sources in NDT applications are growing. With the trend, digital smaller focal spots will become more and more important. With the trend to process integrated applications where throughput is key, small focal spots at high power will gain significance. Additionally to that, availability and system uptime will be key for the near future.

With the HP-Technology and the ability to provide adjustable focal spots, COMET has already a first solution for the existing and future requirements. The spring loaded cable is the first step into the maintenance free $\mathrm{x}$-ray source future.

\footnotetext{
${ }^{1}$ Data and images provided by YXLON
} 
With the wide range of new and innovative products COMET provides already today $\mathrm{x}$-ray sources at best suited for nearly all challenges. Especially with the XRS-225VF resolution with unexpected power can be already achieved today.

\section{BIBLIOGRAPHY}

[1] COMET HOLDING AG, Annual Report 2009, Flamatt,CH,vol.2009,15-23, April (2010), Document available at: http://www.comet.ch/en/investor-relations/financial-reports-presentations/annualreports, visited in Feb13, 2011 10:53am.

[2] COMET HOLDING AG, Annual Report 2002, Flamatt,CH,vol.2002,4-26, April (2003) Document available at: http://www.comet.ch/en/investor-relations/financial-reports-presentations/annualreports , visited in Feb10, 2011 18:43pm RJ.

[3] BS EN 12543-1:1999, Non-destructive testing. Characteristics of focal spots in industrial X-ray systems for use in non-destructive testing. Scanning method, British-Adopted European Standard

[4] ASTM STANDARD, E1025-05, Standard Practice for Design, Manufacture, and Material Grouping Classification of Hole-Type Image Quality Indicators (IQI) Used for Radiology, American Society for Testing and Materials. 